variety, and when such interference takes place the tone is always meagre, as described by Dr. Huggins.

But it will naturally occur that there must be one note in the scale of the instrument which will coincide in its vibrations with those of the belly when in this unsupported condition, and that this note ought to be exceptionally loud. It is so in fact, but not to the extent that might at first be supposed. This is because in reality, as I shall try to explain, the injurious effect of interference does not include the whole question. When a tuning-fork is struck and held out of contact with a resonant body, it gives out a very feeble sound. The cause of this, as is well known, is that each half-wave is compensated and partly annulled by the succeeding half taking place in the opposite direction. A string stretched between two non-resonant supports does the same when plucked or bowed in the middle. In like manner, the belly of a fiddle, when unsupported by a soundpost, is under conditions which are very similar to those of the string. The most yielding part is immediately beneath the bridge, under the impulses of which every point of every longitudinal fibre moves up and down in the same phase, and every half-vibration cancels the effect of the half immediately preceding. The sound is correspondingly feeble. The wave, in fact, is not a true one. It is a to-and-fro, self-compensating motion all along the line. If the bridge were placed near one end of the instrument, the ca:e would be different. Its nearness to a support or fulcrum on one side would cause the free part on the other side to break into a wave of progression, which is the true dynamic sound-giving wave. The office of the sound. post is precisely this. It forms a node at a particular part under the influence of which the wave is converted into one of contrary phases all over the surface. Such a wave travels in wood at amazing rapidity, and the consequence is that every half vibration reaches its limit and strikes the air almost before the other half has commenced its career, and therefore before it has bad time to interfere with its dynamic effect. The best position of the node is found to be just behind the E string, because the higher the note the greater is the firmness required. The $\mathrm{G}$ string is further removed from the support, because the lower notes require greater freedom of motion, but it still partakes of its advantages.

I have never met with a satisfactory explanation of the cause of resonance in sound-boards. It cannot be due to extended surface in the sense that there are more extended vibrations or more numerous ones, because the greater the quantity of matter put in motion the more is the motion diluted. The investigation is practically a difficult one, owing to the extreme minuteness of the oscillations which have to be traced, but so far as the experiments indicate which I have been able to devise, the true cause does seem to be what I have been endeavouring to explain. A resonant wave is a travelling wave-the crest is alwavs in advance of the depression, and expends itself dynamicaliy before the latter has time to neutralise it. On the other hand, the depression succeeds in due order and produces a similar effect. It is in this sense only that an extended surface is useful and necessary.

If we need confirmation of the principle thus advanced, we have it in every wind instrument without exception. The type of all such instruments is the reed, the only difference being that in some it is aërial, and in others substantial. Take therefore an ordinary harmonium reed, and vibrate it with the finger. However elastic it may be, the sound is of the feeblest character. The double vibration is a compensated one--but let a current of air traverse the point of disturbance, the reed then speaks, or rather the current of air speaks. The half vibration has proceeded so far from its origin that it expends its dynamic force before the succeeding half is able to reach and neutralise it - the crest of the wave, as it were, has smitten the shore, before the depression has had time to overtake it. The depression then succeeds and does its own work.

Middlesbrough

\section{Waking Impressions}

THE accompanying experience may be of interest to some of your readers; and that it may be the more genuine in the recounting of it, I copy the little entry I made in my notebook some few hours only after the occurrence, as it was so distinctly impressed on my mind that I could not but be struck by it as being worth taking note of.

I have not unfrequently been on the point of noting down similar visual impressions between sleeping and waking time, but have hitherto always found that they were really of so fugitive a nature, or the mind so little sensitive as not to be retentive, that the mere effort to recall them and put them into uttered words (whether audibly or only mentally uttered) was quite sufficient to dispel the impression totally ; though by a long directing of the memory I could sometimes nearly recover it, not perfectly enough, however, to feel confident that imagination had not added somewhat to the picture. But the present case has been so vividly impressed on my mind that it has been fairly caught, to my own satisfaction at any rate, and I hope that it may be not unworthy of a corner in your valuable paper.

\section{"Reigate, Fuly $\mathbf{3}$}

" This morning I woke up suddenly with the end of a dream and found myself reading, as if from a printed book, only there was no book, merely printed words, thus: 'So while hewas enjoying himself at . . . . she was in deep depression at Kä̈-ro.' The 'Kaÿ-ro' looked quite right, and I quite naturally pronounced it Cairo, and knew I meant that town. I was so struck by the clearness of the visual impression that, for fear of losing it, as one generally does, I instantly recounted the thing to my husband; but in the uttering of it when wide awake I could not at the moment, even so soon after the dream, recollect the name of the other locality (marked here by '. . . . '), though I knew that it had been printed and read by myself in the dream. But about four minutes later, as we were talking it over, I said, 'It is so strange, for I'm sure I've not been talking or thinking either of Beloochistan or Cairo!' and at once it flashed upon me that Beloochistan had been the other name, and I had then and there reseen the impression after an interval of total oblivion of it.

"There had been no idea of book or sheet to carry the printing, nor, I fancy, even solidity of any kind in the letters; but that the whole phrase was conveyed to my mind through a printed form and by a process of reading I am quite certain. We were on a visit, and the night before had been greatly entertained by the conversation of our host, who had been a great traveller, and we had certainly talked much of India, Cashmere, and Assam ; but as far as I can now, or could then, recollect, we had most certainly not mentioned either Beloochistan or Cairo, nor had I been reading a novel before going to sleep or during the previous day."

Collingwood, Hawkhurst, July I4

J. Maclear

\section{Tertiary Corals}

I SHALL be obliged if you or any of your readers would kindly inform me the best authority to consult on the tertiary corals of Piedmont and Liguriz; also the age of the beds in the lower part of Val d'Andona.

Bearsted House, Maidstone, July I5

\section{Wild Fowl and Railways-Instinct and Intelligence}

I AM happy to find that my experience of " ducks and railways" is confirmed by so high an authority as Mr. Goodsir from observations made on the other side of the world. Agreeing so far, we differ as to the cause by which the birds are influenced, Mr. Goodsir attributing it to "quick and unerring instinct," whilst I credit the ducks with "quick intelligence" or reasoning powers. If caused by the "teaching" of instinct, the ducks should show no alarm on the sudden and first appearance of a smoking, roaring train in their midst. They certainly do at first show alarm, but as they receive no injury, their intelligence teaches them, after a brief experience, that there is no danger.

I may perhaps be permitted to give one of many instances known to me of the quickness of birds in acquiring a knowledge of danger. Golden plover, when coming from their breedingplaces in high latitudes, visit the islands north of Scotland in large numbers, and keep together in great packs. At first they are easily approached, but after a very few shots being fired at them, they become not only much more shy, but seem to measure with great accuracy the distance at which they are safe from harm ; the sportsman, however, not unfrequently takes an unfair advantage of them by loading with a wire cartridge, which adds twenty yards or so to the distance at which the gun will kill when charged in the ordinary way.

It would be easy to adduce many cases of what may be considered pure and true instinct, of which the following is perhaps not a bad example, and not unworthy of mention, if it has not already appeared in the columns of NATURE or elsewhere :- 